\title{
COVID-19 in India: Weighing Schools Reopening Amid Black Clouds of Third Wave Hovering Around
}

\author{
Vikas Gupta ${ }^{1}$, Abhishek Singh ${ }^{2, *}$ \\ ${ }^{\prime}$ Department of Community Medicine, Government Medical College, Shahdol, Madhya Pradesh, INDIA. \\ ${ }^{2}$ Department of Community Medicine, SHKM Government Medical College, Nalhar, Haryana, INDIA.
}

The Coronavirus disease (COVID-19) wreaked havoc across the globe with the onset of year 2020, which posed an extra ordinary situation in front of mankind. The black clouds of third wave are still hovering around us.

We all have seen a lot of ups and downs with respect to every front of this disease including restriction of movements and closure of schools. In the current scenario, many voices are being heard to reopen the school with a justification that if we don't open the schools then we going to witness a generation that has missed months or years of schooling. In this regard, we must weigh the decision or consideration of reopening of schools against amid third wave predictions in near future.

\section{School closure across the globe and in India}

The government of India on March 16, 2020, announced closure of all the educational institutions including schools, colleges and universities. According to UNICEF, the COVID-19 pandemic has battered education systems around the world, as there are currently more than 1.2 billion children in 186 countries affected by school closures due to the pandemic. In India, over 1.5 million schools closed down due to the pandemic, affecting 286 million children from pre-primary to secondary levels. This adds to the 6 million girls and boys who were already out of school prior to COVID-19. ${ }^{[1]}$

To fight back the disruption and damage, educational institutes across the country embraced the digital mode of education as a solution to fill the void left by classroom teaching. While the COVID-19 pandemic has made online education the buzzword, in a School Children's Online and Offline Learning (SCHOOL) survey, says that only $8 \%$ of school students in rural India and $24 \%$ of schools in urban India have been able to access online education. ${ }^{[2]}$ The emphasis on technology-driven education is also alienating many children from the underprivileged sections, as a mere $5 \%$ of the children from these groups had access to online classes whichpreventing them from continuing their studies. Even other stakeholders are struggling. Teachers are not always trained and equipped to transition to online teaching.

\section{Impact of school closure on students}

The prolonged closure of schools has been the relation between the teachers and students in both urban and rural sectors with 51\% of the respondents in the urban areas and 58\% in rural India saying that they had not met teachers during the month preceding the survey. ${ }^{[3]}$ In addition to education, the closure most importantly affected the level of nutrition among the children in rural schools where the mid day meals have been stopped.In the absence of alternative options, working parents often leave children alone when schools close and this can lead to risky behaviours, including increased influence of peer pressure and substance abuse. It is a challenge to ensure children and youth return and stay in school when schools reopen after closures. When schools shut down, early marriages increase, more children are recruited into militias, sexual exploitation of girls and young women rises, teenage pregnancies become more common, and child labour grows.

Although a limited number of studies are available reporting health consequences of the COVID-19 school closure, but it has resulted due to restriction of their movement, it may have led to an increase in physical inactivity and sedentary behavior contributed by an increase in daily screen time (video games, time spent on internet, television, mobile phones). ${ }^{[4]}$ Suspected short and long-term consequences of these behavioral changes, ranging from overweight to mental health issues, need further investigation.

\section{Paediatric cases during COVID-19 pandemic across the} globe and in India

Data from China and the United States suggest that pediatric COVID-19 constitutes just $\sim 2.0 \%$ of all reported positive. ${ }^{[5]}$ Children of all ages are susceptible to COVID-19, including newborns.5 Among them, those with respiratory failure due to severe acute respiratory infection (SARI) or multiorgan dysfunction syndrome due to multisystem inflammatory syndrome in children (MIS-C) require critical care. In a scenario of 5\% cumulative pediatric infection proportion, the projected estimate of sick children requiring hospitalization is just $\sim 0.2 \% .10$ Among children $<18$ years of age in the United States, there were $>1.2$ million positive tests for SARS-CoV-2 between March and December 2020, Preschool (age 0 through 4 years) - 17.4 percent; Elementary school (age 5 through 10 years) - 25.7 percent; Middle school (age 11 through 13 years) - 18.6 percent; and High school (age 14 through 17 years) - 38.3 percent. Similarly, children of all ages can get COVID-19 and the incidence increases with increasing age. ${ }^{[6]}$

Many health experts had initially raised concerns about the possibility of a third wave affecting children more adversely than adults. However, recent scientific data suggests otherwise. The Indian Academy of Paediatrics found that there is no biological evidence that the current and the new Delta Plus variant will affect children more disproportionately than adults. ${ }^{[7]}$ The Lancet COVID-19 Commission India Task Force has also concluded that there is no current evidence that an anticipated third wave will target children specifically. A serological survey conducted between March to June 2021 where around 45,000 samples were collected across 4 states by the All India Institute of Medical Sciences (AIIMS) and it suggested that the hypothesis of a future wave specifically targeting children (two years and above) is unfounded. The study noted a serological prevalence of $55.7 \%$ in ages 2-17 years and $63.5 \%$ among adults which clearly determines that there was statistical difference in prevalence between adults and children. ${ }^{[8]}$ The Lancet COVID-19 Commission India Task Force report also points that though children have milder disease and low mortality rate as compared to adults, those with underlying comorbidities might be at higher risk. ${ }^{[9]}$ 


\section{Gupta and Singh.: School Reopening Amid Third Wave of COVID-19}

\section{Comparison of COVID-19 morbidity and mortality pattern with other diseases}

In children, COVID-19 is a comparatively rare cause of death. Data on the characteristics of fatal form of COVID-19 in pediatric patients are scarce. Study from China reported 5.6\% of children with severe disease and $0.6 \%$ of children developing multiorgan failure or acute respiratory distress syndrome (ARDS). ${ }^{[10]}$ Oualha et al. in their series, reported 7\% children with neurological involvement or dysfunction. ${ }^{[1]}$

The causes of under-5 deaths in India in 2017 were lower respiratory infections (17.9\%), neonatal preterm birth (15.6\%), haemolytic disease and neonatal jaundice and other neonatal disorders (14.3\%), diarrhoeal diseases (9.9\%), neonatal encephalopathy due to birth asphyxia and trauma (8.1\%), congenital birth defects $(8.0 \%)$, injuries $(4.1 \%)$, neonatal sepsis and other neonatal infections $(3.5 \%)$, and measles $(1 \cdot 6 \%)$. The causes of neonatal death in India in 2017 were neonatal preterm birth (27.7\%), neonatal encephalopathy due to birth asphyxia and trauma (14.5\%), lower respiratory infections (11.0\%), congenital birth defects (8.6\%), neonatal sepsis and other neonatal infections (6.1\%), haemolytic disease and neonatal jaundice $(3 \cdot 2 \%)$, diarrhoeal diseases $(2 \cdot 7 \%)$, and tetanus $(0 \cdot 7 \%)$. $^{[12]}$

\section{Vaccines for COVID-19 in paediatrics along efficacy and efficiency and side effects in India and other countries}

One of the main concerns regarding vaccinating children and adolescents against SARS-CoV-2 are the lack of sufficient data on vaccine-induced long-term immunogenicity in children and, even more critical-safety data. However, the first results for the Pfizer-BioNTech and Moderna vaccine in children $\geq 12$ years of age are more than promising-vaccine efficacy reached 97-100\%-which has already encouraged several authorities to approve the vaccine in this population. ${ }^{[13]}$ Zydus's India-developed antiCovid ZyCoV-D secured regulatory approval for emergency use, becoming the world's first DNA-based vaccine for the novel coronavirus that will be administered to children above 12 years and adults. The vaccine showed 66\% efficacy against moderate Covid infection and 100\% against severe Covid, preventing serious disease and hospitalisation. Similarly, Bharat Biotech's Covaxinis the only vaccine in the world that can be given to children between 2 and 18 years and its clinical trial final phase is over and data is being submitted to DGCI. ${ }^{[14]}$

\section{Expert opinion regarding school opening}

As many schools have reopened for in-person instruction in some parts of the India as well as internationally, school-related cases of COVID-19 have been reported, but there has been little evidence that schools have contributed meaningfully to increased community transmission. In the fall of 2020, 11 school districts in North Carolina with more than 90000 students and staff were open for in-person education for 9 weeks. During this time, within-school transmissions were very rare (32 infections acquired in schools; 773 community-acquired infections) and there were no cases of student-to-staff transmission. Similarly, in a report released by CDC on January 26, 2021, with data from 17 K-12 schools in rural Wisconsin with high mask adherence (4876 students and 654 staff), COVID-19 incidence was lower in schools than in the community. A European Centre for Disease Prevention and Control report from December 2020 that included findings from 17 country-level surveys found that 12 countries reported from 1 (Latvia) to 400 (Spain) school-based clusters of 2 or more epidemiologically linked SARS-CoV-2 infections, but that overall cluster sizes were small (most $<10$ cases) and could often not be definitively linked to in-school vs community-based transmission..$^{[15]}$

While these data are encouraging overall, large outbreaks have occurred with apparent transmission in schools. In Israel, within 2 weeks of schools reopening in mid-May 2020, a large high school outbreak occurred when 2 students with epidemiologically unrelated infections attended classes while mildly symptomatic. Testing of more than $99 \%$ of at-risk students ( $n=1164$ eligible; 1161 tested) and staff (152 eligible; 151 tested) identified 153 and 25 cases of SARS-CoV-2 infection, respectively (attack rates of 13.2\% and 16.6\%). ${ }^{[15]}$ Contributing factors to this outbreak included crowded classrooms with insufficient physical distancing (eg, student density in classrooms exceeded recommended values), exemption from face mask use, and continuous air conditioning that recycled interior air in closed rooms during a heat wave. Committing today to policies that prevent SARS-CoV-2 transmission in communities and in schools, will help ensure the future social and academic welfare of all students and their education.

\section{Parents for resumption}

Most parents surveyed have supported reopening of the schools at the earliest. Ten percent of the parents in urban areas had some hesitation in sending their children to school but overall $97 \%$ of parents supported reopening of schools. The report said the prolonged school lockdown, one of the longest in the world, has led to a "colossal disaster". ${ }^{[16]}$

\section{Preparedness of states regarding capacity building of schools to prevent transmission of COVID-19 among students}

In view of this, there was a normative need to assess the readiness of the school to reopen in a conducive and safe atmosphere to accept students. An SOP for the voluntary reopening of schools was released by the Ministry of Health and Family Welfare and the Government of India, at the same time (September 8, 2020), which came in as a reinforcement to the line of thought. ${ }^{[17]}$ In a brainstorming session with the school principal and teachers, suggestions were gathered from their side to implement measures that could lead to a safe environment in the school.

\section{Preparedness for COVID-19 among Paediatric age group}

Since the children below 18 years remain unvaccinated in India, this fact has created a sense of worry among some public health experts. Also, the existing pediatric health care facilities are not robust enough to treat children on a large scale. Epidemics have the maximum impact on a country's future, hence, the GoI has opted for a cautious and proactive approach and directed all hospitals to allocate $20 \%$ of their beds for children. For children with MIS-C, who test negative for acute COVID, care has to be provided by the existing pediatric facilities and these facilities also need augmentation especially HDU and ICU services. Majority of children have asymptomatic or mild illness and can be managed at home by parents. In a community setting, ASHA / MPW will be involved for management of children at home and also monitor to assess the need for referral/admission. Telemedicine will be harnessed for reaching out to large number of facilities. ${ }^{[18]}$

\section{CONCLUSION}

At the end of this discussion, it is concluded that schools should be reopened with certain precautions and thorough capacity building of school administration and teachers to prevent transmission of COVID-19 among students. Vaccination of school teachers must be taken care of as a 


\section{Gupta and Singh.: School Reopening Amid Third Wave of COVID-19}

universal rule. At the same time, we must be prepared and keep a vigilant eye on the raising cases of COVID-19 in order to take quick decision on reversal of such foreword move.

\section{CONFLICT OF INTEREST}

The authors declare that there is no conflict of interest.

\section{REFERENCES}

1. Press release, UNICEF. COVID-19: Schools for more than 168 million children globally have been completely closed for almost a full year [cited 28/10/2021]. Available from: https://www.unicef.org/press-releases/schools-more-168-millionchildren-globally-have-been-completely-closed.

2. The times of India. Survey: $37 \%$ poor rural students not studying at all [cited 1/11/2021]. Available from: https://timesofindia.indiatimes.com/ home/education/news/survey-37-poor-rural-students-not-studying-at-all/ articleshow/85991577.cms.

3. Alam A, Tiwari P. Implications of COVID-19 for low-cost private schools [cited 26/10/2021]. Available from: https://www.unicef.org/globalinsight/media/1581/ file/UNICEF_Global_Insight_Implications_covid-19_Low-cost_Private_ Schools_2021.pdf.

4. Lim RBT, Wee WK, For WC, Ananthanarayanan JA, Soh YH, Goh LML, et al. Correlates, facilitators and barriers of physical activity among primary care patients with prediabetes in Singapore - a mixed methods approach. BMC Public Health. 2020;20(1):1. doi: 10.1186/s12889-019-7969-5. PMID 31898494.

5. CDC COVID-19 Response Team. Coronavirus disease 2019 in children-United States, February 12-april 2, 2020. MMWR Morb Mortal Wkly Rep. 2020 Apr 10;69(14):422-6. doi: 10.15585/mmwr.mm6914e4, PMID 32271728.

6. Nande A, Sheen J, Walters EL, Klein B, Chinazzi M, Gheorghe AH, Adlam B, et al. The effect of eviction moratoria on the transmission of SARS-CoV-2. Nat Commun. 2021 Apr 15;12(1):2274. doi: 10.1038/s41467-021-22521-5, PMID 33859196

7. Sitlhou M. Children, Covid-19, and India's looming third wave. BMJ. 2021;374:n2328. doi: 10.1136/bmj.n2328, PMID 34561215.

8. COVID-19 third wave preparedness. New Delhi: Children's Vulnerability and
Recovery, National Institute of Disaster Management [cited 2/11/2021]. Available from: https://nidm.gov.in/PDF/pubs/TWPCVR_2021.pdf.

9. Alsaied T, Aboulhosn JA, Cotts TB, Daniels CJ, Etheridge SP, Feltes TF, et al. Coronavirus Disease 2019 (COVID $\square$ 19) pandemic implications in pediatric and adult congenital heart disease. J Am Heart Assoc. 2020 Jun 16;9(12):e017224. doi: 10.1161/JAHA.120.017224, PMID 32441586.

10. Singh A, Saini I, Meena SK, Gera R. Demographic and clinical profile of mortality cases of COVID-19 in children in New Delhi. Indian J Pediatr. 2021 Jun;88(6):610. doi: 10.1007/s12098-021-03687-8, PMID 33689110.

11. Oualha M, Bendavid M, Berteloot L, Corsia A, Lesage F, Vedrenne M, et al. Severe and fatal forms of COVID-19 in children. Arch Pediatr. 2020 Jul 1;27(5):235-8. doi: 10.1016/j.arcped.2020.05.010, PMID 32518045.

12. India State-Level Disease Burden Initiative Child Mortality Collaborators. Subnational mapping of under- 5 and neonatal mortality trends in India: The Global Burden of Disease Study 2000-17. Lancet. 2020 May 23;395(10237):1640-58. doi: 10.1016/S0140-6736(20)30471-2, PMID 32413293.

13. Pfizer and BioNTech announce positive topline results from pivotal trial of covid-19 vaccine in children 5 to 11 years [cited 3/11/2021]. Available from: https:// www.pfizer.com/news/press-release/press-release-detail/pfizer-and-biontechannounce-positive-topline-results.

14. Coronavirus disease (COVID-19): vaccines. Available from: https://www.who.int/ news-room/q-a-detail/coronavirus-disease-(covid-19)-vaccines [cited 3/11/2021].

15. Honein MA, Barrios LC, Brooks JT. Data and policy to guide opening schools safely to limit the spread of SARS-CoV-2 infection. JAMA. 2021 Mar 2;325(9):823-4. doi: 10.1001/jama.2021.0374, PMID 33497433.

16. The Times of India [cited 26/10/2021]. Available from: https://www.thehindu.com/ news/national/survey-details-catastrophic-impact-of-school-closures-acrossindia/article36309490.ece.

17. Directorate General of Health Services (EMR Division). Government of India. Government of India [cited 26/10/2021]. Available from: https://www.mohfw.gov. in/pdf/FinalSOPonpartialresumptionofactivitiesinschools8092020.pdf.

18. Ministry of Health and Family Welfare, Government of India [cited 3/11/2021]. Available from: https://www.mohfw.gov.in/pdf/ GuidelinesonOperationalizationofCoVIDCareServicesforChildrenand Adolescents14062021.pdf.
Received: 28 August 2021;

Accepted: 27 October 2021

*Correspondence to:

Dr. Abhishek Singh, MBBS, $M D$, Associate Professor, Department of Community Medicine, SHKM Government Medical College, Nalhar, Haryana, INDIA. Phone no: +91-8199001422

Email:abhishekparleg@gmail.com

Copyright: (C) the author(s),publisher and licensee Indian Academy of Pharmacists. This is an open-access article distributed under the terms of the Creative Commons Attribution Non-Commercial License, which permits unrestricted non-commercial use, distribution, and reproduction in any medium, provided the original work is properly cited.

Cite this article as: Gupta V, Singh A. COVID-19 in India: Weighing Schools Reopening Amid Black Clouds of Third Wave Hovering Around. J Pharm Pract Community Med. 2021;7(3):41-3. 